\title{
Emulating Excitation System of a Biomass-Based Micro Steam Turbine Generator
}

\author{
Khairudin $^{1, *}$ Amirudin $^{1}$ L Hakim ${ }^{1}$ H Gusmedi $^{1}$ U Hasanudin ${ }^{2}$ A Haryanto ${ }^{2,3}$ \\ ${ }^{1}$ Department of Electrical Engineering, Universitas Lampung, Jl. S. Brodjonegoro No.1, Bandar Lampung, Indonesia \\ ${ }^{2}$ Tropical Biomass Research Center, Universitas Lampung, Jl. S. Brodjonegoro No.1, Bandar Lampung, Indonesia \\ ${ }^{3}$ Department of Agricultural Engineering, Universitas Lampung, Jl. S. Brodjonegoro No.1, Bandar Lampung, \\ Indonesia \\ ${ }^{*}$ Corresponding author. Email: khairudin@eng.unila.ac.id
}

\begin{abstract}
An Arduino-driven power supply was applied to control the electromagnetic field of a synchronous machine experimented in this work. Typically, electromagnetic field was controlled by adjusting the field current. In this work, the field was directly controlled by regulating voltage source of the exciter using pulse width modulation signal. In the development of this emulator, an AC induction motor was used to mimic the prime mover of the generator system, coupled with synchronous electric generator. Various loads were utilized to capture responses of the developed controller. These loads included induction motor, lightings, and combinations of resistors and inductors for emulating different power factors of the loads. The proportional integral differential (PID) control was adopted in the emulator and capable of emulating various models of generator voltage controller. Different PID settings were exercised in the laboratory. Results of the experiment using some loading conditions showed this kind of excitation method is capable of mimicking the real synchronous generator excitation system. Since various models of generator unit may be used in the power plant and each of them has particular characteristics of response, this emulator also has the capability to follow that response characteristic by adjusting the PID parameters.
\end{abstract}

Keywords: Micro steam turbine, PID control, synchronous machine, power plant emulator, biomass

\section{INTRODUCTION}

The utilization of renewable energy sources derived from biomass is increasingly widespread in Indonesia, especially in Lampung. This is possible considering there are a lot of available resources, whether from sugarcane waste, palm oil waste and cassava waste. The production of electricity attained from biomass will only be economically feasible if the selling price and market absorption can compete for the cost of production. Connecting this power plant to the National Grid (PLN) is the only way for the project to grasp the break event point (BEP) in the appropriate time.

The problem now is that connecting these biomass plants to the PLN grid is not trivial. Various network configuration scenarios should be analyzed and simulated before being applied to the real system. Simulations using software do not always give satisfactory results because not all parameters can be modeled precisely. Therefore, an emulator capable of mimicking the characteristics of a real biomass power plant is required.

An emulator is a device that attempts to mimic the behavior of a real resource. It is compounded by two interrelated parts, a software and a hardware layer [1]. In this study hardware layer consists of an induction motor, generator and other devices explain in section 2 of this paper. The software layer was developed in Arduino to manage the PID constants as well as interface software installed on a personal computer to monitor and record measurement data.

Two aspects oblige a regulation on the real biomass power station that employs synchronous generators as the generating engines. First is the torque of the prime mover which must always be able to maintain the rotor rotation 
at the synchronous speed. The second is adjusting the field strength of the excitation system to keep the generator terminal voltage at its nominal value. This study purposely dealing with excitation field control by using Arduino as a controller unit based on the input terminal voltage associated with the induced emf on the field winding. The adjustment of the prime mover torque is carried out in a separate study from this work.

This paper is a part of a broad research project emulating a smart microgrid system conjoining power system technology, computer control and information and communication technology. Figure 1 shows the global architecture of the research in power system laboratory, Lampung University.

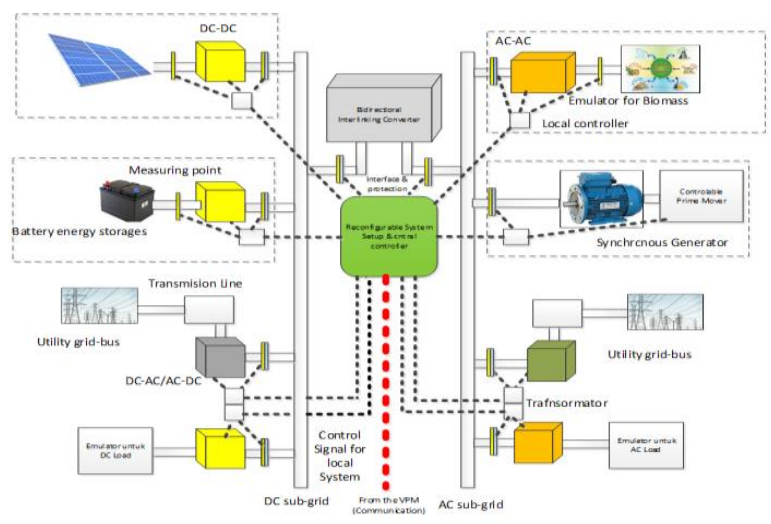

Figure 1 Conceptual diagram of a smart grid emulator

\section{METHOD}

\subsection{PLACE AND TIME}

The Arduino-driven power supply was applied to control the electromagnetic field of the synchronous machine. Unlike the common excitation system in real power plant where the electromagnetic field is regulated by attuning the field current controlled by an Automatic Voltage Controller (AVR) [2][3], here the field was directly controlled by regulating the voltage source of the exciter using pulse width modulation signal. Since the system regarded as a closed loop with the feedback acquired from the machine output terminal, then the PID method was employed in the control system.

The prime mover represented by a three-phase induction motor (IM). Since the study focuses on the performance of field winding control, the IM speed assumed to remain constant, and its torque proportionally follows the load torque. The indirect effect of governor response to the terminal voltage was neglected.

Figure 2 and Figure 3 show the block diagram and prototype of biomass power plant emulator respectively. The prototype of the emulator consists of a 3-phase AC Power Supply for powering IM. Synchronous Generator was driven by IM representing a steam turbine and its governor, voltage sensor for feedback input to the microcontroller, Arduino with PID controller to adjust PWM signal need for regulating field current, Electrical loads and relays circuit and a computer unit.

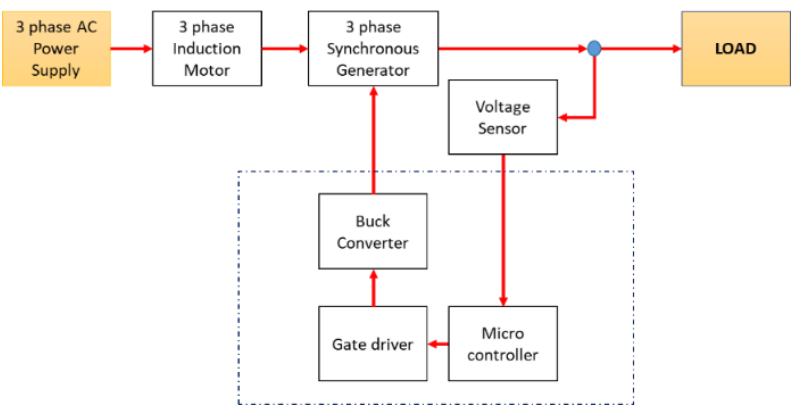

Figure 2 Block diagram of a biomass power plant emulator

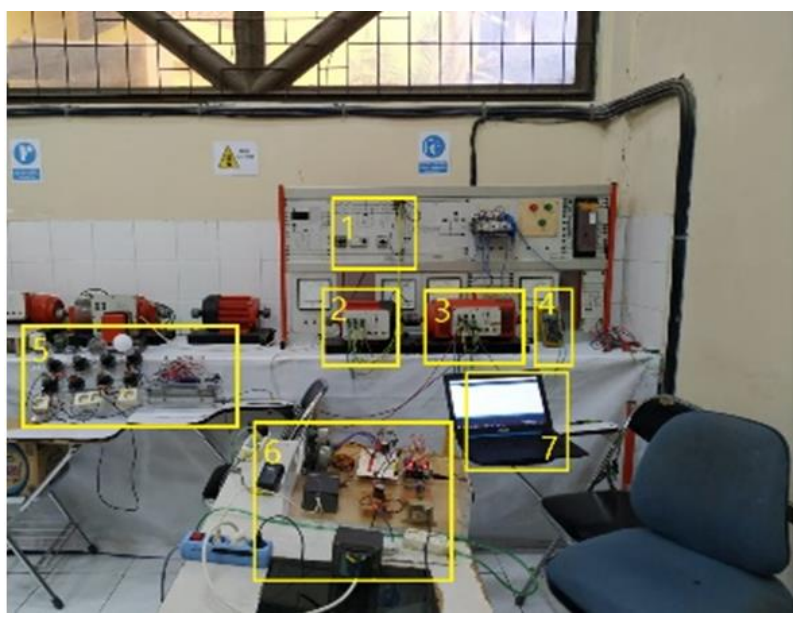

Figure 3 Biomass power plant emulator prototype

The arrangement of the prototype emulator as shown in Figure 3 is described as follows. Yellow boxes are to identify the equipment used in the experiments. Box (1) indicates an AC power supply to run the motor as the prime mover. Box (2) is an AC induction motor driving the generator. Box (3) is a single-phase generator. Box (5) is the lighting load and box (6) is the developed controller system.

The equivalent circuit for the biomass synchronous generator is given in figure 4 . In this work, VF was adjusted to manipulate the induced voltage to EA instead of tuning up RF as in real generator excitation system.

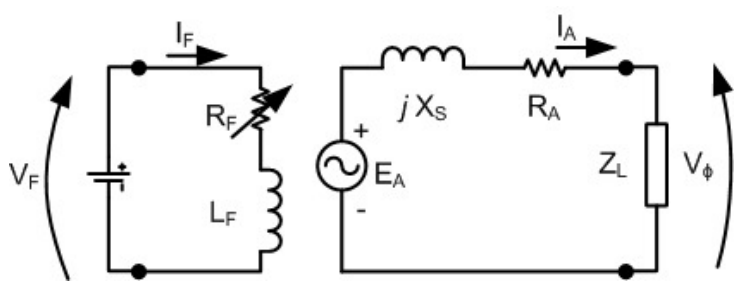

Figure 4 Perphase equivalent circuit for biomass synchronous generator emulator

To mimicking a certain type of synchronous generator excitation characteristic, constant parameters 
on the PID algorithm were manipulated. PID algorithm consists of KP, KI and KD where KP, KI and KD stand for proportional, integral and differential constant respectively. The electromagnetic field controller is driven by the difference between the reference value VRef (the references are supposed to be constant since typically only step variations are required) and the measured value of the terminal voltage per phase $\mathrm{V} \square$ [3]. By adjusting different PID parameters, assorted types of generator excitation control can be achieved.

The synchronous generators excitation control systems are designed with controllers that allow a lot of setting flexibility to the operator to achieve an optimum generator terminal voltage response [4]. In the reduced model, the generators terminal voltage is the output, the generator and exciter blocks are reduced to the first order model. $\mathrm{K}_{\mathrm{G}}$ is the forward gain of the generator, and $t_{g}$ and $t_{e}$ are the generator and exciter time constants, respectively. The controller used to control the terminal voltage of the generator is a PID controller [4][5][6]. Figure 5 depicts the PID control transfer function used in this study.

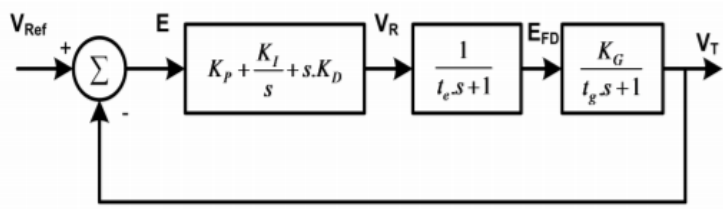

Figure 5 Transfer function of PID control of excitation emulator

\section{RESULTS AND DISCUSSIONS}

Voltage control in the real electric network varies following the load change. Hence, it is important to verify this characteristic on the emulator. Figure 6 shows the increase in load resulting in a decrease in voltage when there is no field regulation by the exciter. Figure 7 depicts the response of the excitation system on controlling terminal voltage after attaching a 590 Watt load.

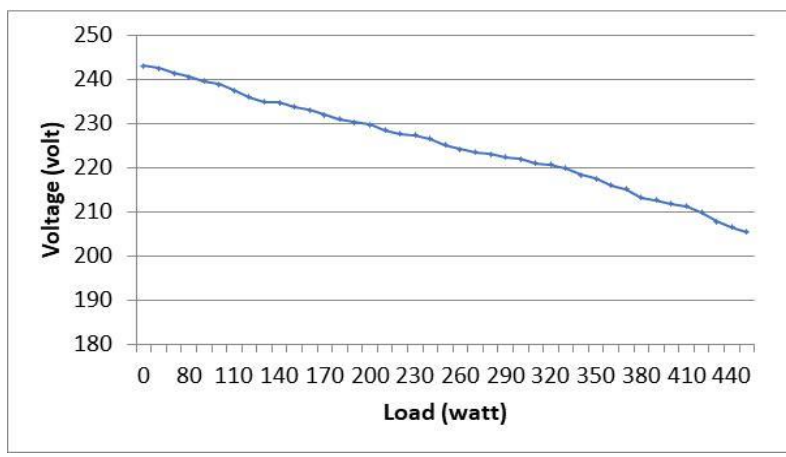

Figure 6 P-V curve of generator terminal voltage

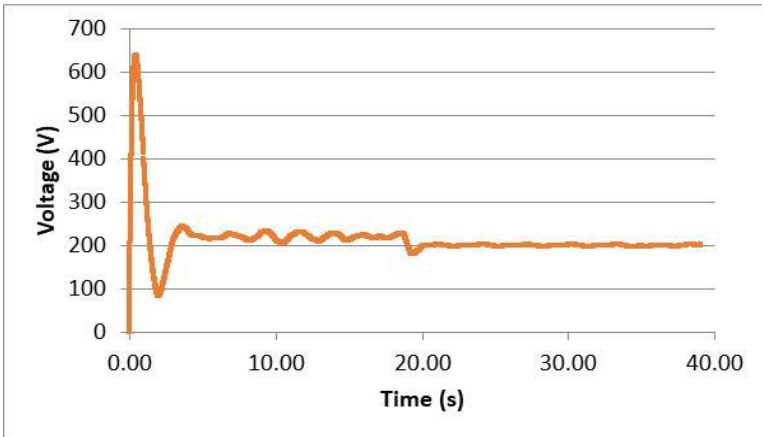

Figure 7 Voltage control response upon switching on 590 watt lighting loads

To apprehend the performance of the emulator, different loading conditions were attached to it. Figure 8 shows the voltage control response for $40 \mathrm{~s}$ upon switching on 590 watts of incandescent lamps simultaneously at about $20 \mathrm{~s}$ after the generator started. As expected, the generator terminal voltage after this switching was unable to be brought back to its rated RMS value of 220 volt due to a large amount of load connected. A smaller amount of lighting loads of 150 watts was also simulated. Figure 9 indicates that for this case, the generator terminal voltage was still at about its rated voltage of 220 volt.

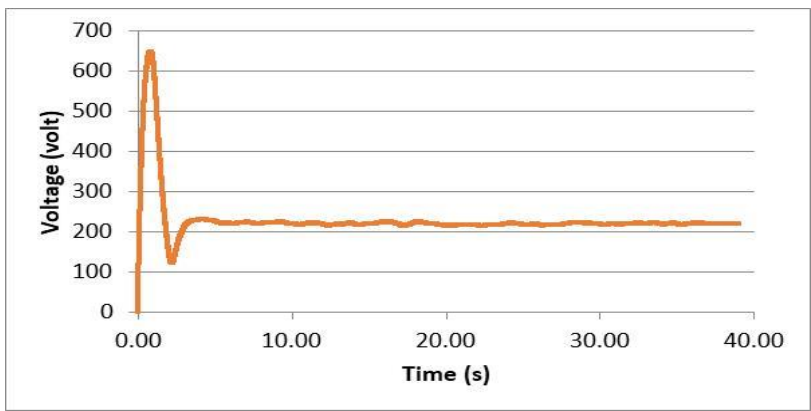

Figure 8 Voltage control response upon switching on 150 watt lighting loads

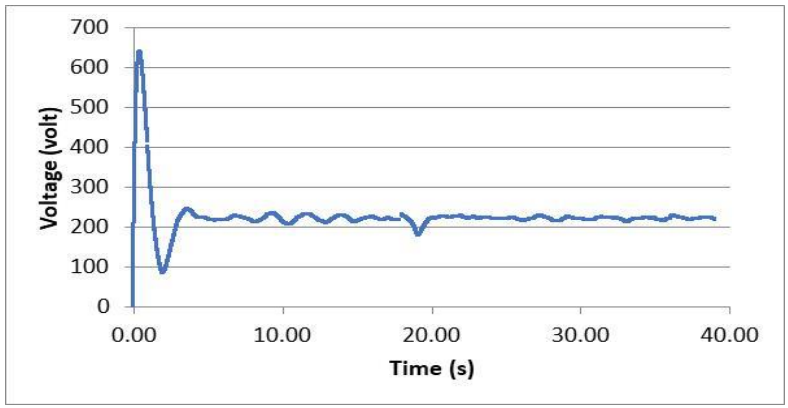

Figure 9 Voltage control response upon switching on 125 Watt no-load AC motor

Changing the load type to AC motor shows that 125 Watt AC motor although during the starting of such motor it is observed a transient sag of the generator terminal voltage. It is different from a static load, such as 
an incandescent lamp where no sag was observed. The generator terminal voltage returned to its nominal voltage within about 1 second.

The proposed controller system is based on PID control and therefore its performance under various PID parameters is shown in figure 10. These plots show voltage variations results from the proposed excitation control system during 40 seconds measurements. Different PID parameters were set to the proposed system and the emulator system responded to these settings. The top four plots show the proportional and integral parameters while the other lower four plots show voltage variation with all three proportional, integral and differential parameters set. This feature is important if the developed system is required to emulate different actual generator's excitation system. Prior knowledge of the excitation system to be emulated can be obtained from manufacturer of such generator.
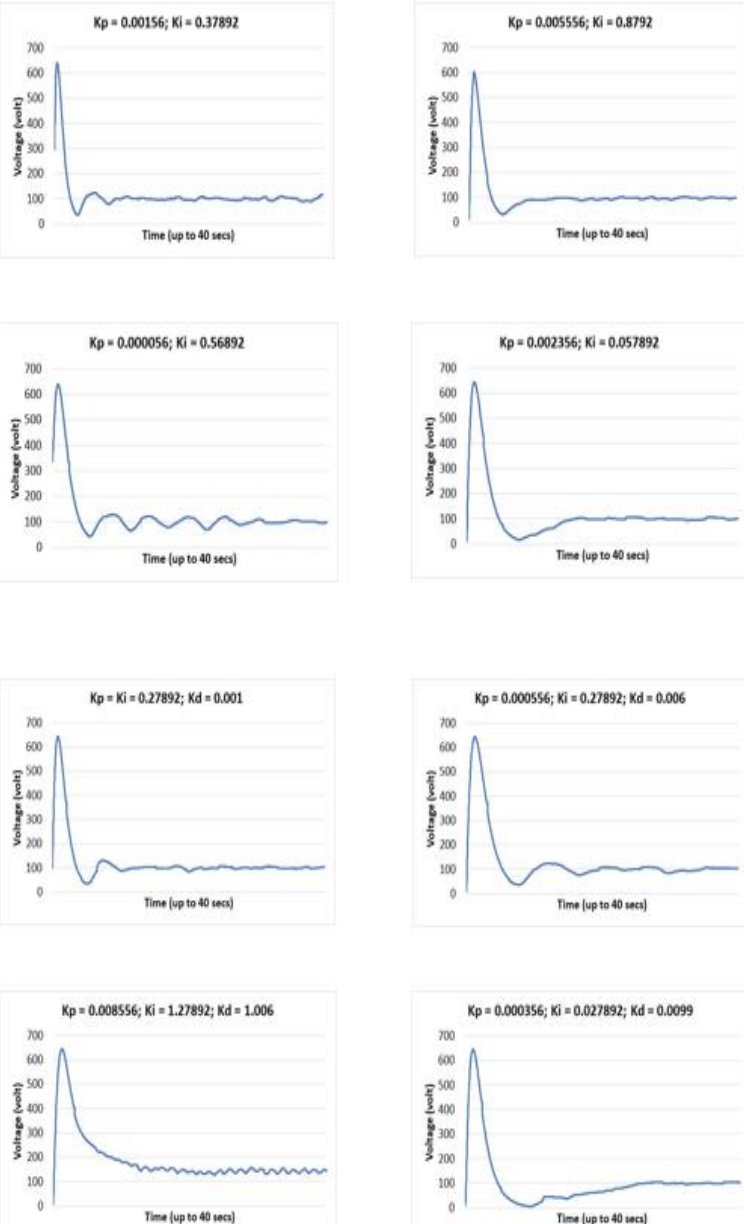

Figure 10 Control response for various PID parameters

\section{CONCLUSIONS}

This work proposed an excitation system for a biomass-based micro steam turbine generator based on PID control. The developed prototype is part of a complete emulator for the microgrid system. It was tested in the laboratory under various loading conditions and different PID settings, and it successfully performed as expected. This ability to perform excitation control under different PID settings is important feature of such emulator, in this case an emulator for excitation system of a biomass-based micro steam turbine generator.

\section{REFERENCES}

[1] E. Prieto-Araujo, P. Olivella-Rosell, M. CheahMañe, R. Villafafila-Robles, O. Gomis-Bellmunt, 2015, Renewable energy emulation concepts for micro grids. Renewable and Sustainable Energy Review (Volume 50, October 2015). pp. 325-345

[2] J. Machowski, J.W. Bialek, S. Robak, J.R. Bumby, 1998, Excitation control system for use with synchronous generators. IEE Proceedings Generation, Transmission and Distribution (Electronic Materials vol 145 No. 5) pp. 537-546.

[3] A. Bonfiglio, F. Delfino, M. Invernizzi, A. Perfumo, R. Procopio, 2012, A Feedback Linearization Scheme for the Control of Synchronous Generators. Electric Power Components and Systems (Electronic Materials vol 40. N. 16), pp. 1842-1869.

[4] D.M. Sajnekarb, L. Mohan, S.B. Kolhea, R.M. Deshpandec, R. M. Moharilb, N.P. Patidard, K. Ogura, 2018, Design of PID controller for automatic voltage regulator and validation using hardware in the loop technique. International Journal of Smart Grid and Clean Energy (Electronic Materials Vol 7), pp. 75-89.

[5] A. Godhwani, M.J. Basler, 1996, A digital excitation control system for use on brushless excited synchronous generators. IEEE Transactions on Energy Conversion. (vol 11, No. 23), pp. 616-620.

[6] K. Kiyong, C.S. Richard, 2005, Design of PID controller for automatic voltage regulator and validation using hardware in the loop technique. IEEE Transactions on Industry Applications. (Vol. 41, No. 5), pp. 485-492. 